\title{
Investigation of Open Abdomen Visceral Skin Graft Revascularization and Separation from Peritoneal Contents
}

\author{
Katharine E. Caldwell1, Ross M. Clark1, Brittany B. Coffman², Jacquelyn S. Brandenburg1, \\ Thomas R. Howdieshell ${ }^{*}$
}

${ }^{1}$ Departments of Surgery, University of New Mexico Health Sciences Center, Albuquerque, USA

${ }^{2}$ Pathology, University of New Mexico Health Sciences Center, Albuquerque, USA

Email: ^thowdieshell@salud.unm.edu

How to cite this paper: Caldwell, K.E., Clark, R.M., Coffman, B.B., Brandenburg, J.S. and Howdieshell, T.R. (2018) Investigation of Open Abdomen Visceral Skin Graft Revascularization and Separation from Peritoneal Contents. Surgical Science, 9, 24-43.

https://doi.org/10.4236/ss.2018.91004

Received: December 1, 2017

Accepted: January 21, 2018

Published: January 24, 2018

Copyright $\odot 2018$ by authors and Scientific Research Publishing Inc. This work is licensed under the Creative Commons Attribution International License (CC BY 4.0).

http://creativecommons.org/licenses/by/4.0/

c) (i) Open Access

\begin{abstract}
Background: Despite increasing survival following damage control laparotomy and open abdomen technique, little is known about the biology of visceral skin graft revascularization and separation from peritoneal contents. Methods: Following laparotomy for trauma, patients with visceral edema preventing fascial closure underwent Vicryl mesh closure followed by visceral split-thickness skin grafting and readmission graft excision and abdominal wall reconstruction. Utilizing laser speckle contrast imaging, immunochemical staining of histologic sections, and RT-PCR array technology, we examined the revascularization, microvascular anatomy, morphology, and change in gene expression of visceral skin grafts. Results: Ten patients ranging in age from 25 to 46 years underwent visceral grafting for cutaneous coverage of an open abdomen. Skin graft perfusion peaked at a mean of $350 \mathrm{PU}$ by post-operative day 14 synchronous with closure of meshed interstices, and remained constant until excision. Time to graft excision ranged from 6 to 18 months. CD-31 immunostaining documented a significant $(p=0.04)$ increase in vascular surface area in excised grafts compared to control skin. Trichrome staining revealed an 8-fold increase in excised graft thickness. Mesothelial cells were identified within the dermal matrix of excised grafts. RT-PCR demonstrated significant up-regulation of genes involved in matrix structure and remodeling, cytoskeleton regulation, and WNT signaling; and down-regulation of genes involved in inflammation and matrix proteolysis in excised grafts compared to control skin. Conclusion: Our data document early visceral skin graft perfusion and a plateau in revascularization. Histology reveals a robust dermal matrix populated by fibroblasts and mesothelial cells within a complex supporting vascular network. Genetic analysis of excised grafts reveals growth factor, collagen, and matrix remodeling gene expression.
\end{abstract}




\section{Keywords}

Open Abdomen, Visceral Skin Graft, Mesothelial Cells

\section{Introduction}

Currently, between $10 \%$ and $15 \%$ of trauma laparotomies are performed utilizing damage-control surgery techniques [1]. Damage-control surgery is most often used to control exsanguinating hemorrhage in patients with severe physiological derangement or high-risk injury pattern [2]. Hemorrhagic shock and required crystalloid and blood product resuscitation result in visceral edema often preventing primary fascial closure of the abdominal wall [3]. As a result, definitive abdominal wall repair is preceded by a period of temporary abdominal wall closure [4] [5]. If early primary fascial closure is not practical or feasible, techniques have been reported for management of the open abdominal defect including closure with an absorbable mesh to provide a scaffold for visceral granulation tissue formation and cutaneous coverage by split-thickness skin graft (STSG) [6] [7].

The timing of definitive abdominal wall reconstruction following visceral skin grafting is determined by evaluating the characteristic adherence of the split-thickness skin graft to the underlying viscera. Initially, the graft remains firmly adherent to exposed viscera. However, over a 6 to 12 months interval, the adhesions between graft and viscera become pliable, and the skin graft can be pinched away from the underlying viscera allowing graft excision and successful abdominal wall reconstruction [8] [9].

Despite innovative research in resuscitation physiology, temporary abdominal closure techniques, nutritional support, and intensive care management which have increased the survival of patients with an open abdomen [10] [11], there has been no investigation into visceral skin graft perfusion, maturation, or separation from peritoneal contents. Utilizing laser speckle contrast imaging (LSCI), immunochemical staining of histologic sections, and reverse transcription polymerase chain reaction (RT-PCR) array technology, we examined the functional revascularization, microvascular anatomy, morphology, and gene expression of visceral skin graft maturation and separation.

\section{Methods}

\subsection{Patients and Temporary Closure Technique}

From January 2013 to January 2016, more than 7400 patients were admitted to the University of New Mexico Hospital level 1 trauma center. Ten patients $(0.14 \%)$ required temporary abdominal closure and visceral split-thickness skin grafting and are the subject of this research. This study was approved by the Human Research Review Committee and the Scientific Review Committee of the Human Tissue Repository of the University of New Mexico Health Sciences 
Center. Informed consent was obtained from all patients. Patients were identified and data was tabulated using our trauma registry and patient medical records under HIPAA compliance.

Patients with open abdominal wounds which were not amenable to primary fascial closure underwent temporary closure by insertion of knitted Vicryl mesh (Polyglactin 910 Mesh, Ethicon, Inc., Somerville, NJ) to prevent evisceration. The mesh was sutured to the abdominal wall fascia using a running monofilament suture. The mesh was covered with Mepitel Silicone Sheeting (MoInlycke Health Care, Gothenburg, Sweden) followed by a black foam-containing wound VAC (Vacuum Assisted Closure, Acelity/KCI, San Antonio, TX) at $125 \mathrm{~mm} \mathrm{Hg}$ suction. The VAC was changed every 48 hours until granulation tissue covered the mesh and underlying viscera. Following granulation tissue maturation, cutaneous coverage was provided by application of a 0.015 inch thick split-thickness skin graft harvested from the thigh using a Zimmer dermatome (Zimmer Inc., Warsaw, IN). The STSG was meshed at 2:1 ratio using a Brennan mesher (MoInlycke Health Care). Mepitel and a wound VAC were applied over the STSG and remained in place until post-operative day (POD) 5.

After hospital discharge, each patient was followed in the outpatient clinic to examine visceral STSG maturation and measure graft perfusion by LSCI. When the skin graft became pliable and was able to be pinched away from underlying viscera, the patient was scheduled for graft excision and definitive abdominal wall reconstruction.

\subsection{Laser Speckle Contrast Imaging}

Prior to skin grafting (open abdomen granulation bed and thigh donor site), immediately after graft application, at wound VAC removal (POD 5), and at post-operative intervals of 1 week, 2 weeks, 1 month, 2 - 4 months, and graft excision, laser speckle contrast imaging was performed with the Full-Field Laser Perfusion Imager (FLPI, Moor Instruments, Essex, UK). Real-time data was acquired in Live Image Measurement Mode. The contrast images were processed to produce a scaled color-coded Live Flux Image (red, high perfusion; blue, low perfusion) which correlated with the blood velocity in the tissue [12].

\subsection{Donor and Visceral Skin Graft Harvest, Histology, and Immunochemical Staining}

Each visceral skin graft was surgically excised from the abdominal wall and underlying peritoneal contents. Following excision, seven full-thickness biopsies (each $5 \mathrm{~cm}^{2}$ ) were performed using sterile technique with tenotomy scissors and included two left lateral, two right lateral, and three central locations. Each biopsy was bisected, and one-half of the tissue was fixed in $10 \%$ buffered formalin for 24 hours, processed, and paraffin-embedded. Serial sections ( $4 \mu \mathrm{m})$ were dewaxed in xylene, taken through graded ethanol, hydrated in phosphate-buffered saline, and stained with Hematoxylin and Eosin (Vector Laboratories, Burlingame, CA), Trichrome (Trichrome Staining Kit, 860-031, Ventana Medical Sys- 
tems, Roche Diagnostics, Indianapolis, IN), or immunohistochemical technique (below). The remaining one-half of each biopsy was immersed in RNAlater RNA stabilization reagent (Qiagen, Valencia, CA) and stored at $4^{\circ} \mathrm{C}$ for later RNA isolation and purification. A portion of harvested and meshed thigh split-thickness skin which was not grafted onto visceral granulation tissue was processed in identical fashion and used as a histologic and molecular control.

Blood vessel, myofibroblast, smooth muscle cell, and mesothelial cell identity were determined by CD-31, $\alpha$-smooth muscle actin ( $\alpha$-SM actin), calretinin, and Wilms tumor antigen-1 (WT-1) immunostaining. After dewaxing and hydration, sections were incubated for 10 minutes in 3\% hydrogen peroxide in methanol to block endogenous peroxidase activity, washed in phosphate-buffered saline, and incubated with primary antibody (CD-31, clone JC70A, 1:100, Dako Agilent Pathology Solutions, Santa Clara, CA; $\alpha$-SM actin, clone SP171, 1:100, Abcam Inc., Cambridge, MA; calretinin, polyclone, 1:100, Zymed Technologies, Thermo Fisher Scientific, Waltham, MA; WT-1, clone 6F.H2, 1:10, Dako) for 30 minutes at room temperature in a humidified chamber. Next, the sections were incubated with secondary antibody using the Benchmark Ultra Instrument (Ventana Medical Systems, Inc.) and manufacturer's protocol followed by the 3,3'-diaminobenzidine chromogen (DAB) (Ultra-View DAB Detection Kit, Ventana Medical Systems, Inc.) for light microscopy. The sections were counterstained with Vector Hematoxylin QS (Vector Laboratories) with quick immersion. The $\mathrm{DAB}$ chromogen resulted in a brown-colored precipitate at the antigen site.

\subsection{Microvascular Density Determination}

Control skin and excised skin graft vessel counts and vascular luminal cross-sectional surface areas were determined with image analysis of CD-31 immunostained sections. Each full-thickness biopsy was analyzed with a total mean value reported for each region of interest using a previously reported technique [13].

\subsection{RNA Isolation and Purification}

The RNeasy Fibrous Tissue Kit (Qiagen) was utilized for RNA isolation using a previously reported technique. The purity of the isolated RNA was confirmed by a spectrophotometric ratio $\left(\mathrm{A}_{260} / \mathrm{A}_{280}\right)$ of 1.9-2.1, and by sharp bands for $28 \mathrm{~S}$ and $18 \mathrm{~S}$ ribosomal RNA on agarose gel electrophoresis [14].

\subsection{Gene Expression Analysis by Quantitative Real-Time PCR Array}

The $\mathrm{RT}^{2}$ Profiler PCR Array System (SA Biosciences, Frederick, MD) was utilized to analyze the expression of a focused panel of genes using SYBR green-based real-time PCR. Each PCR array is a 96-well plate containing the RT ${ }^{2}$ PCR primer assays for a set of 84 genes, plus five housekeeping genes and three controls. Human Wound Healing Pathway Array (PAHS-121Z) was used to 
examine the mRNA levels of genes involved in wound remodeling and repair according to manufacturer's protocol. The PCR primer sequence of each gene analyzed is available on the manufacturer's web site.

Arrays were performed on control skin and excised visceral skin graft. The relative change in each gene expression was determined by first normalizing the value to the average of select housekeeping genes. Changes in expression of a particular gene between control skin and excised skin graft were quantified by comparing the difference in cycle threshold $\left(\mathrm{C}_{\mathrm{t}}\right)$ values $\left(\Delta \Delta \mathrm{C}_{\mathrm{t}}\right)$ after normalization. Values for controls and excised skin grafts were used in the calculation of fold change only if their $\mathrm{C}_{\mathrm{t}}$ value was $<35$ confirming expression [15].

\subsection{Statistical Analysis}

All data are expressed as the mean values \pm standard error of the mean. Statistical analysis was performed with SPSS 15.0 software (SPSS Inc., Chicago, IL). Differences between baseline and subsequent time points were determined with repeated-measures analysis of variance with Tukey significant difference test used for post hoc analysis. Analysis of two samples was performed with Student's t-test. All calculations and statistical analysis of the PCR array data were performed by accessing PCR Array Data Analysis Web Portal (available at: http://superarray.com/pcrarraydataanalysis.php). A p value of 0.05 or less was considered statistically significant.

\section{Results}

\subsection{Patient Demographics and Clinical Course}

Ten patients with persistent visceral distension with or without abdominal wall tissue loss preventing direct fascial closure were managed with split-thickness skin grafting of visceral granulation tissue. There were 7 men and 3 women, ranging in age from 25 to 46 years (mean $34 \pm 8$ years). Seven patients sustained blunt injuries secondary to motor vehicle, motorcycle, or pedestrian/motor vehicle crash; and 3 patients were victims of penetrating trauma from gunshot or stab wounds. The mean Injury Severity Score (ISS) was 30 (range 20 - 54), and mean Abdominal Trauma Index (ATI) was 28 (range 4 to 56).

The interval to split-thickness skin grafting of the open abdominal wound was dependent on the development of mature visceral granulation tissue, varying from 14 to 35 days (mean $18 \pm 9$ days) after Vicryl mesh closure. Granulation occurred more rapidly if omentum was present to cover exposed bowel. The skin grafted surface area ranged from 200 to $1000 \mathrm{~cm}^{2}$ (mean $430 \pm 150 \mathrm{~cm}^{2}$ ), the largest wounds resulting from persistent visceral edema with traumatic abdominal wall tissue loss (Figure 1). Skin graft take rate was greater than $95 \%$, and no patient required repeat grafting.

Definitive abdominal wall reconstruction was performed when the visceral skin graft became pliable and separable by palpation from the underlying peritoneal contents, ranging from 5 to 12 months (mean $6 \pm 2$ months) after grafting 


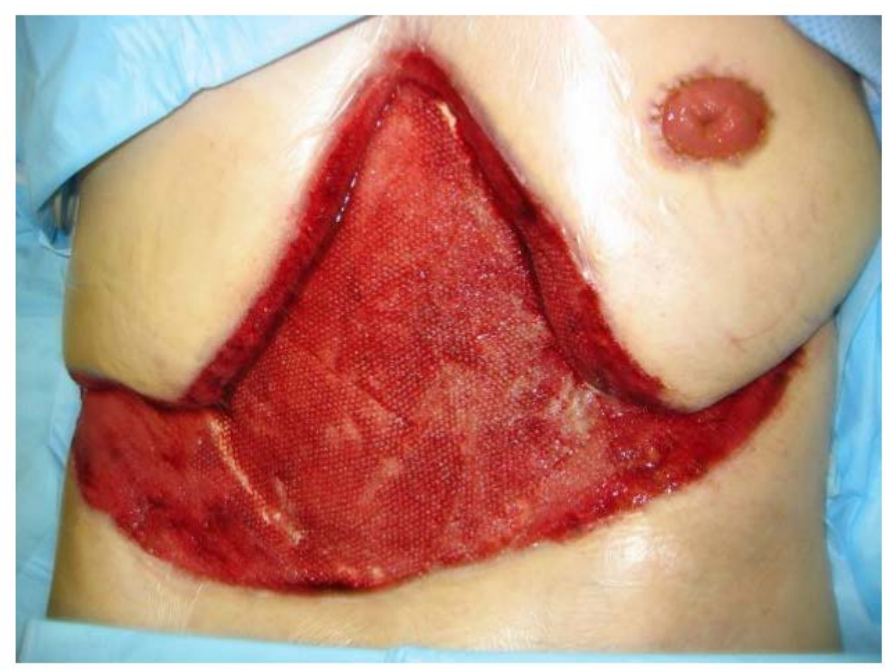

(a)

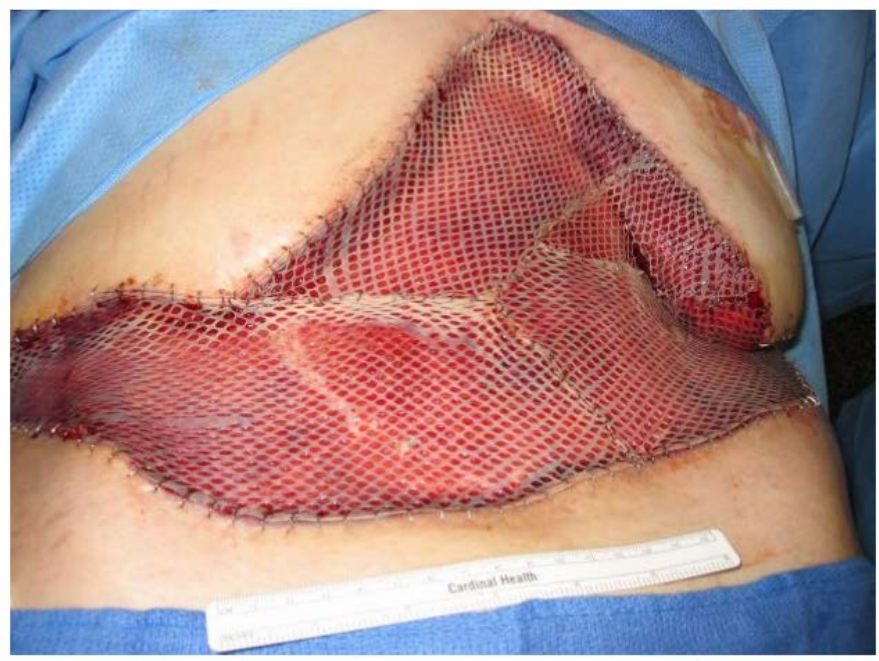

(b)

Figure 1. (a) Visceral granulation tissue covering large open abdomen defect secondary to seat belt full-thickness disruption of the abdominal wall. Note left upper quadrant colostomy; (b) Application of meshed split-thickness skin graft to visceral granulation bed.

(Figure 2). Five patients required tissue expansion for definitive reconstruction which delayed graft excision to 18 months in 2 patients. Therefore, the time to skin graft excision ranged from $6-18$ months (mean $9 \pm 3$ months) following visceral grafting.

Skin graft excision was performed by incision at the graft-native abdominal wall junction with mobilization of the graft away from peritoneal contents by sharp dissection. The undersurface of the graft was white in color and possessed the physical characteristics of dermis (Figure 3). Focal serosal and omental adhesions existed, and graft excision was performed without enterotomy. Definitive abdominal wall closure was accomplished by direct primary fascial closure, component separation fascial release, pedicled myofascial tissue transfer, and/or use of prosthetic mesh. 


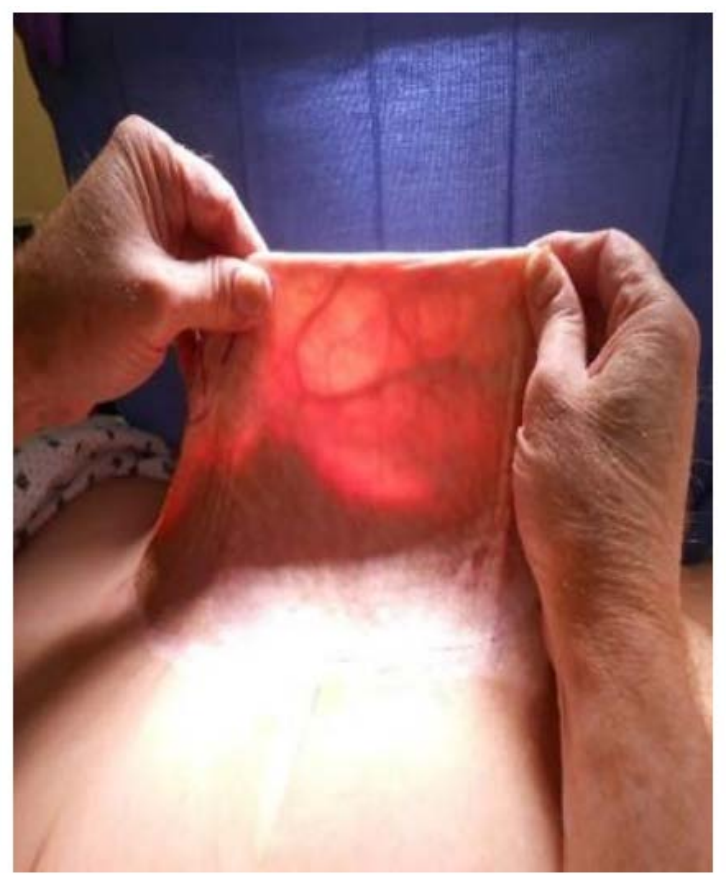

Figure 2. Transillumination of visceral skin graft pinch test at 6 months after grafting. Note separation of graft from underlying peritoneal contents.

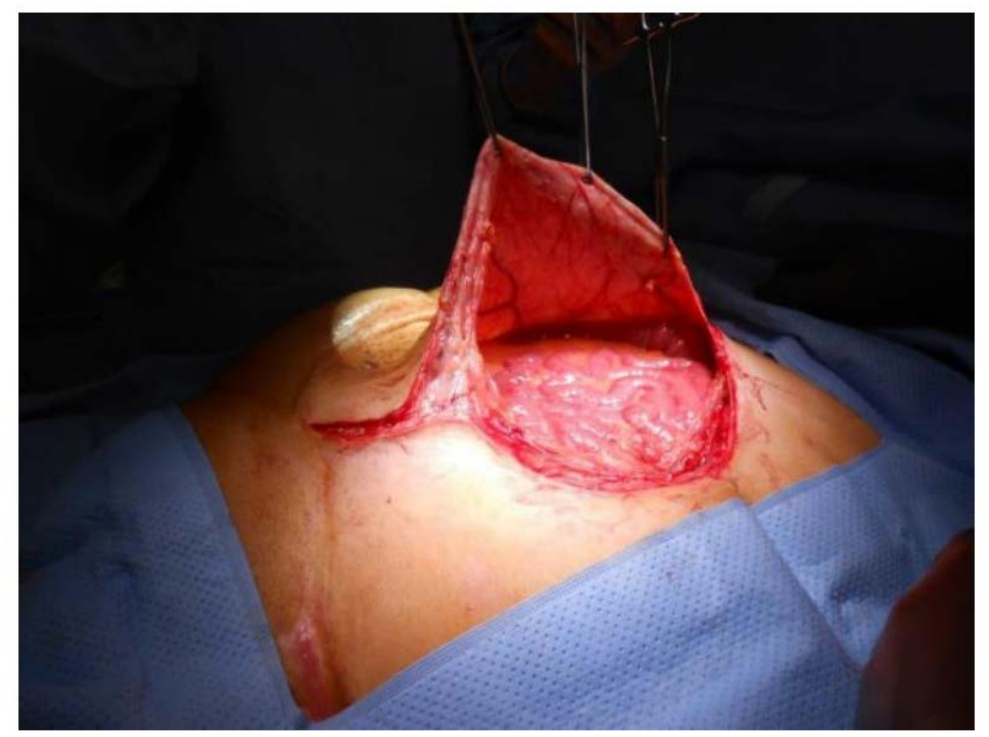

Figure 3. Operative excision of visceral skin graft. Note the glistening appearance of its undersurface with enriched vasculature.

\subsection{Laser Speckle Perfusion Analysis}

The Full-Field Laser Perfusion Imager (FLPI) illuminates an area of tissue with laser light to produce a high contrast random interference effect known as speckle pattern [16]. Compared with laser Doppler imaging, the effective sampling depth of laser speckle imaging in less than $1 \mathrm{~mm}$ [17], ideal for determination of blood flow in the microvasculature of the surface layer of the tissue being examined, for example, donor site skin and visceral split-thickness skin graft. 
Prior to skin graft harvesting and visceral grafting (control), thigh donor site and open abdomen visceral granulation recipient site perfusion was measured and recorded using the FLPI instrument. Thigh cutaneous perfusion, comparable to trunk cutaneous perfusion, ranged from 50 - $90 \mathrm{PU}$ (mean $75 \pm 10 \mathrm{PU}$ ), while pre-graft visceral granulation tissue perfusion ranged from $900-1200 \mathrm{PU}$ (mean $1100 \pm 75$ PU) (Figure 4). Immediately following application of a STSG to the visceral granulation tissue bed (POD 0), measured perfusion declined (range $120-190 \mathrm{PU}$, mean $150 \pm 35 \mathrm{PU}$ ). Verified by high resolution region of interest analysis, this recorded perfusion was simply background granulation tissue perfusion detected through the skin graft meshed interstices confirming the ability of the instrument to discriminate perfusion of the skin graft from underlying tissues (Figure 5). On post-operative day 5, the wound VAC was

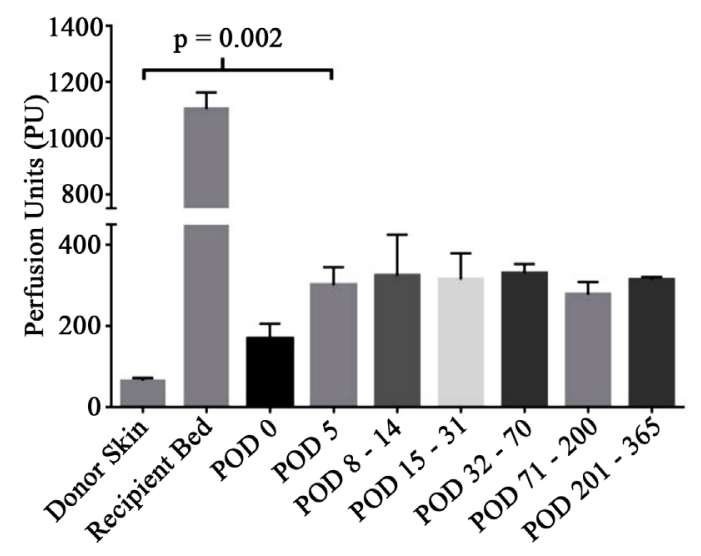

Figure 4. Thigh and visceral skin graft perfusion versus time ( $\mathrm{n}=10$ for each group). Donor skin: Baseline perfusion of thigh donor site skin prior to harvesting. Recipient bed: Baseline perfusion of visceral granulation tissue bed prior to grafting. POD 0: Visceral skin graft perfusion at immediate application to recipient bed. Bracket compares baseline donor site perfusion to visceral skin graft perfusion on POD 5 at wound VAC removal. POD: Post-operative day.

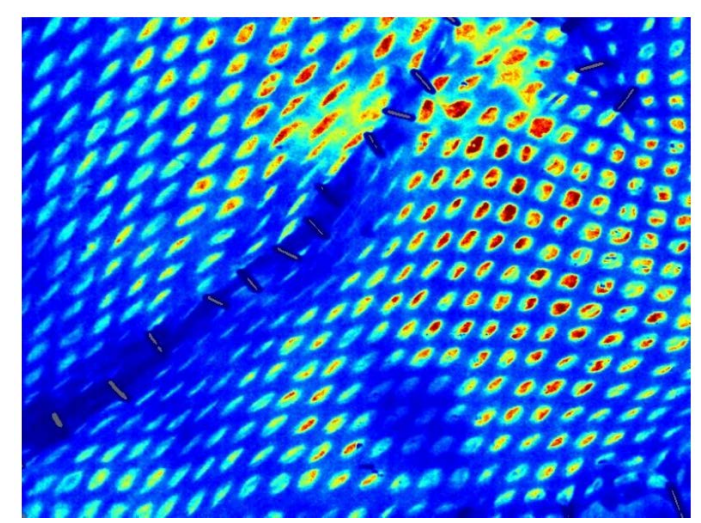

Figure 5. Laser speckle image of visceral skin graft at immediate application on visceral granulation bed (POD 0). Scaled color-coded Live Flux Image (red, high perfusion; blue, low perfusion) which correlated with blood flow velocity in tissue. Note the lack of actual graft perfusion (blue) and presence of background granulation tissue perfusion detected through the meshed interstices (green, yellow, red). 
removed from the graft, and the measured mean skin graft perfusion was $300 \pm 50$ PU (range 250 - $350 \mathrm{PU})$, a significant $(p=0.002)$ four-fold increase in mean perfusion compared to control thigh donor site cutaneous perfusion. By post-operative week 2, visceral skin graft perfusion peaked at a mean value of $350 \pm 90 \mathrm{PU}$, synchronous with complete closure of meshed interstices. Thereafter, graft perfusion remained unchanged until excision (Figure 4).

\subsection{Graft Histopathology}

Trichrome staining of harvested, nongrafted (control) and excised visceral skin graft histologic sections was performed to define subepidermal matrix morphology to accurately determine graft thickness (Figure 6). Histologic examination revealed a significant $(p<0.0001) 8$-fold increase in excised graft thickness compared to control (mean control thickness $400 \mu \mathrm{m}$ vs. mean excised graft thickness $3200 \mu \mathrm{m}$ ). The increase in excised graft thickness was exclusively a result of an increase in the dermal thickness, with no significant change in the thickness of the epidermis, and no evidence of residual Vicryl mesh (Figure 6 and Figure 7).

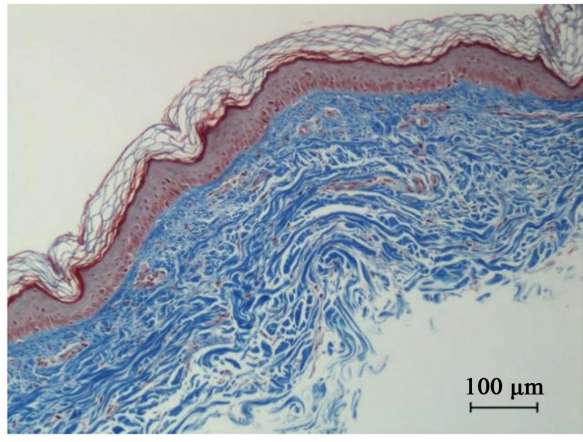

(a)

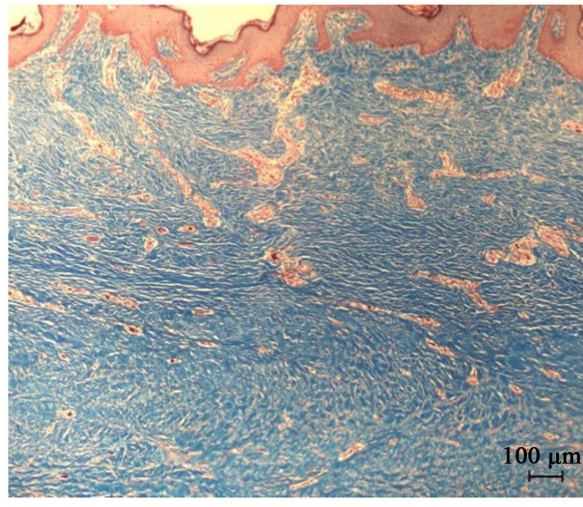

(b)

Figure 6. (a) Trichrome stain of harvested, nongrafted control thigh skin (magnification $100 \times)$. The epidermis appears pink and the dermis is blue. Representative control skin graft thickness is $420 \mu \mathrm{m}$. The scale bar is $100 \mu \mathrm{m}$; (b) Trichrome stain of excised visceral skin graft (magnification 100x). Note the dramatic increase in thickness of the dermal matrix (blue). Representative visceral skin graft thickness is greater than $1200 \mu \mathrm{m}$. The scale bar is $100 \mu \mathrm{m}$. 


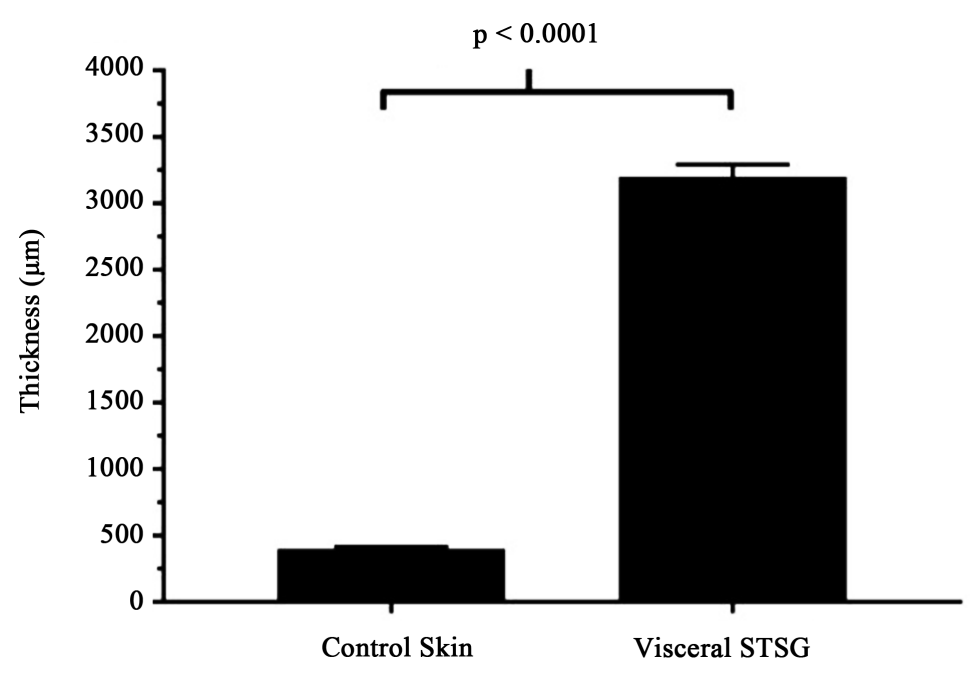

Figure 7. Control skin graft versus visceral skin graft thickness ( $\mathrm{n}=10$ per group). Bracket reveals statistical significance. STSG: Split-thickness skin graft.

To corroborate skin graft perfusion with microvascular anatomy, CD-31 immunostaining and digital image analysis of control and excised graft histologic sections was utilized to determine vessel count and vascular luminal cross-sectional surface area. At comparable depth (less than $500 \mu \mathrm{m}$ or the average thickness of control skin graft), immunostaining documented a 1.2 -fold increase in vessel number, and a statistically significant $(p=0.04) 2$-fold increase in vascular surface area in excised grafts compared to control skin. Analysis of visceral skin graft microvascular anatomy by depth revealed a significant $(p=0.003)$ increase (4-fold) in vascular surface area in the deep (greater than $500 \mu \mathrm{m}$ ) compared to the superficial region of the graft (Figure 8 and Figure 9).

To further characterize the morphology of the interface between visceral skin graft and peritoneal cavity, calretinin and WT-1 immunostaining was utilized to identify and localize mesothelial cells [18]. Colocalization of calretinin and WT-1 immunoreactivity confirmed the presence of mesothelial cells throughout the dermal matrix of the excised skin grafts, primarily in perivascular locations (Figure 10). No immunoreactivity was present in control skin. $\alpha$-SM actin staining, utilized to determine smooth muscle cell and myofibroblast identity [19], revealed the presence of smooth muscle cells in the walls of blood vessels located in control and excised skin grafts, but failed to demonstrate the presence of dermal myofibroblasts in control or excised tissues (Figure 11).

\subsection{Gene Expression}

Quantitative RT-PCR arrays were performed on harvested, nongrafted skin (control) and excised visceral skin grafts to analyze the expression of a focused panel of genes involved in tissue repair. Of the 84 pathway focused genes assayed, $32 \%$ were up-regulated and 5\% were down-regulated in visceral skin grafts compared to control skin. Table 1 reveals visceral skin graft gene expression. Note the up-regulation of genes involved in keratinocyte proliferation and 
Most Superficial $500 \mu \mathrm{m}$

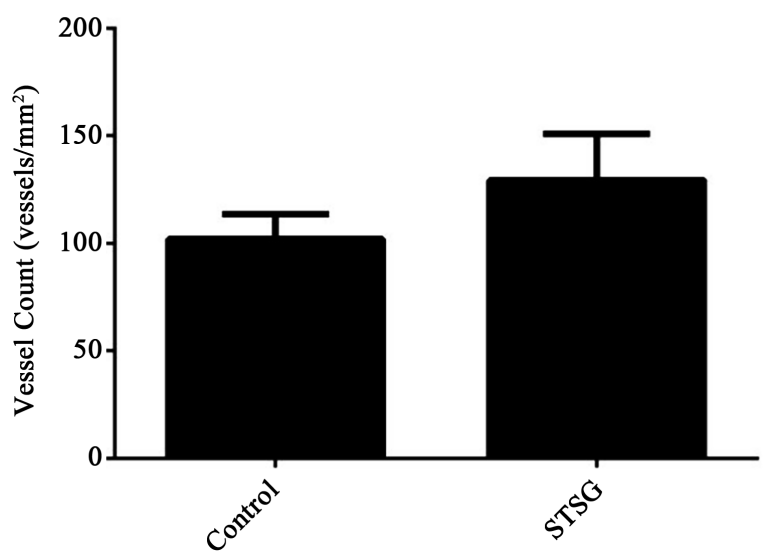

(a)

Most Superficial $500 \mu \mathrm{m}$

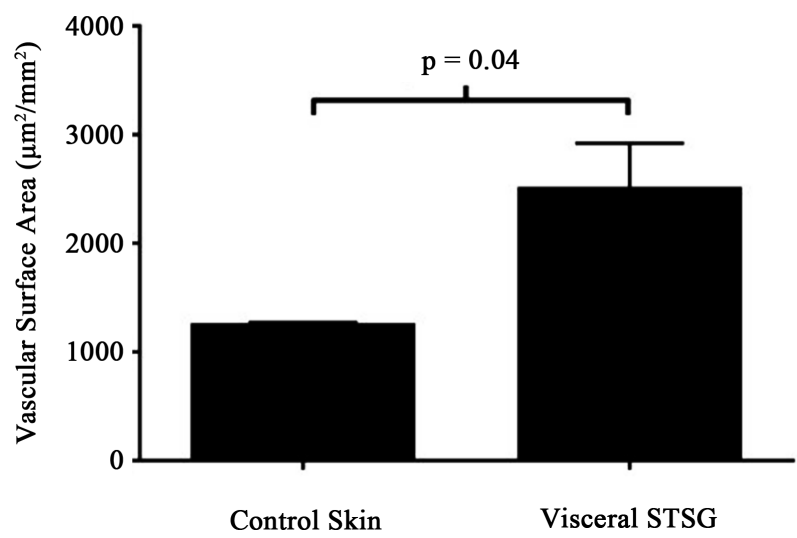

(b)

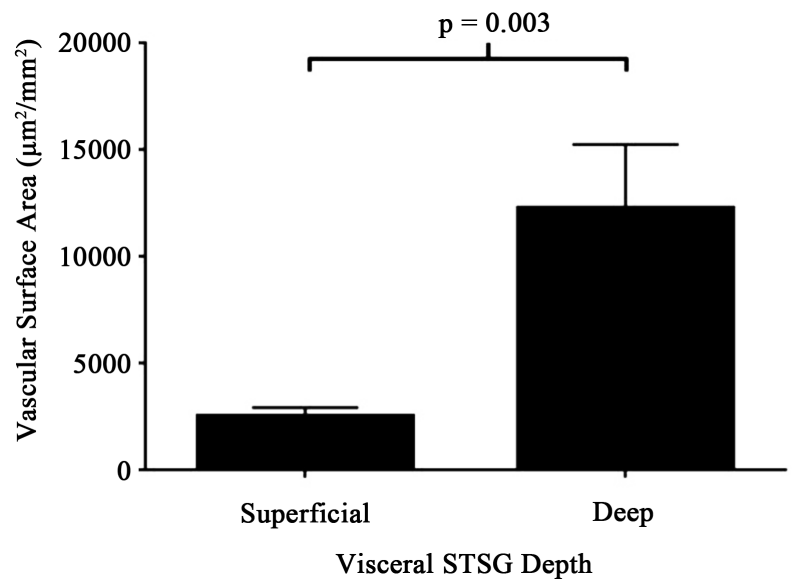

(c)

Figure 8. (a) Vessel counts in control skin graft and visceral skin graft at superficial depth or the average thickness of control skin graft $(500 \mu \mathrm{m})$; (b) Vascular surface area in control skin graft and visceral skin graft at superficial depth $(500 \mu \mathrm{m})$. Bracket reveals statistical significance; (c) Visceral skin graft vascular surface area by depth. Superficial: Less than $500 \mu \mathrm{m}$; Deep: Greater than $500 \mu \mathrm{m}$. Bracket reveals statistical significance. STSG: Split-thickness skin graft. 


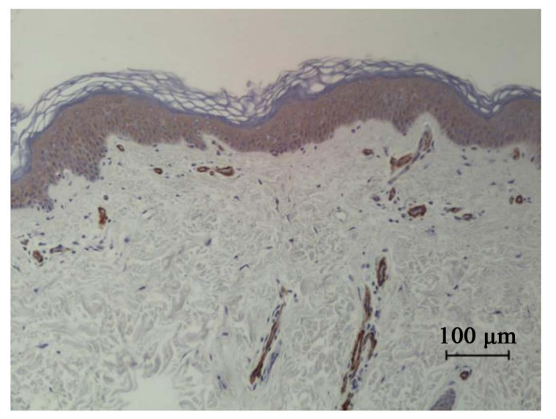

(a)

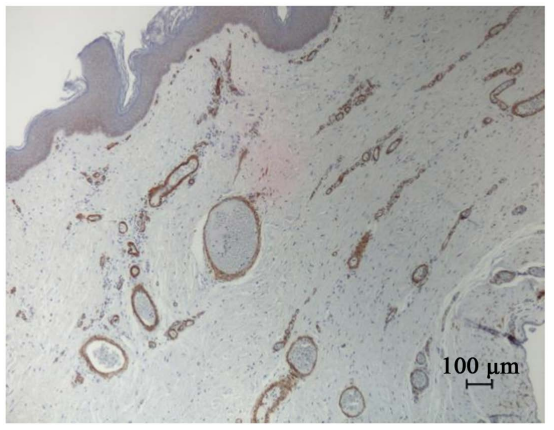

(b)

Figure 9. (a) Histologic section of control skin graft demonstrating the dermal microvasculature (CD-31 immunostaining, endothelium stained brown, magnification $100 \times$, scale bar is $100 \mu \mathrm{m}$ ); (b) CD-31 immunostained histologic section of excised visceral skin graft (endothelium stained brown, magnification $40 \times$, scale bar is $100 \mu \mathrm{m}$ ). Note the numerous large vessels within the thick dermal matrix.

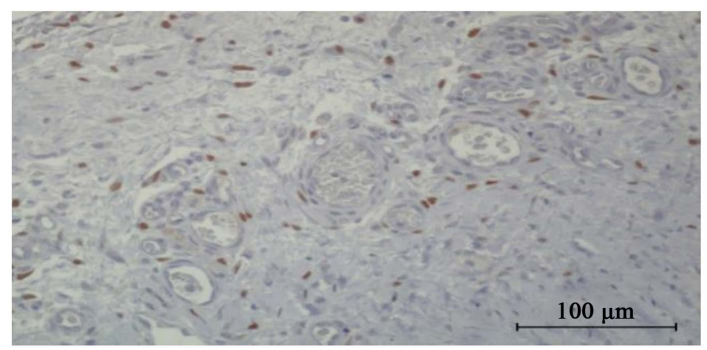

(a)

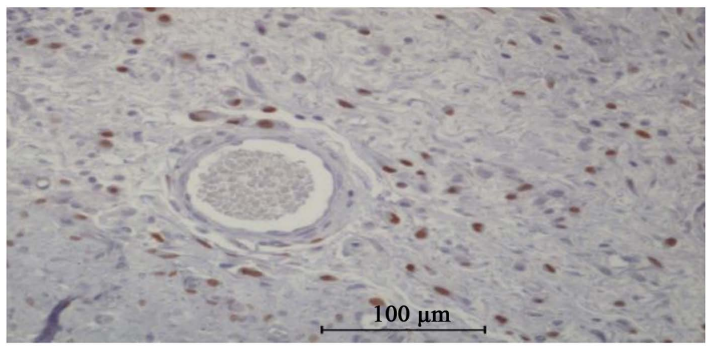

(b)

Figure 10. (a) Histologic section of excised visceral skin graft stained with calretinin primary antibody demonstrating mesothelial cell presence (brown cytosolic staining, magnification $200 \times$, scale bar is $100 \mu \mathrm{m}$ ); (b) High-magnification image of excised visceral skin graft stained with WT-1 primary antibody demonstrating the perivascular presence of mesothelial cells (brown nuclear staining, magnification 200x, scale bar is $100 \mu \mathrm{m}$ ). 


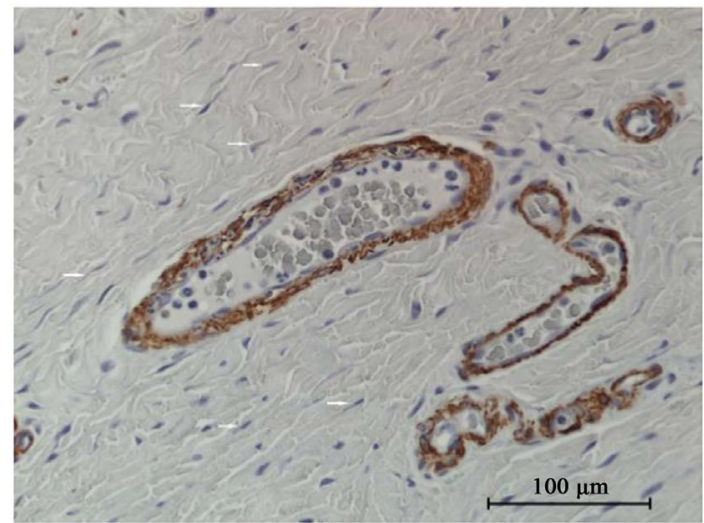

Figure 11. High-magnification photomicrograph (magnification 400x) of visceral skin graft stained with $\alpha$-SM actin primary antibody revealing the presence of vascular smooth muscle cells (brown) and quiescent fibroblasts (arrows). Scale bar is $100 \mu \mathrm{m}$.

Table 1. Visceral skin graft gene expression.

\begin{tabular}{|c|c|}
\hline \multicolumn{2}{|c|}{ Gene Expression } \\
\hline Up-regulated genes & Fold change \\
\hline IGF-1 & $22.6 \pm 2.1$ \\
\hline Serpine (PAI-1) & $20.5 \pm 1.6$ \\
\hline FGF-7 & $9.8 \pm 1.1$ \\
\hline Col 3A1 & $9.1 \pm 0.8$ \\
\hline Col 14A1 & $9.0 \pm 1.1$ \\
\hline Col 1A1 & $8.6 \pm 0.9$ \\
\hline Col 1A2 & $7.8 \pm 1.1$ \\
\hline Col 5A2 & $7.1 \pm 1.0$ \\
\hline Angpt-1 & $6.8 \pm 1.2$ \\
\hline CTGF & $6.5 \pm 1.1$ \\
\hline WISP-1 & $6.1 \pm 0.9$ \\
\hline CTSG & $5.4 \pm 1.0$ \\
\hline CTSK & $3.6 \pm 0.4$ \\
\hline Tagln & $3.5 \pm 0.8$ \\
\hline Col 5A1 & $3.4 \pm 0.2$ \\
\hline FGF-2 & $3.3 \pm 0.6$ \\
\hline ITGA1 & $3.1 \pm 0.7$ \\
\hline ITGB6 & $2.5 \pm 0.3$ \\
\hline TIMP-1 & $2.4 \pm 0.5$ \\
\hline \multicolumn{2}{|l|}{ Down-regulated genes } \\
\hline MMP-7 & $-11.2 \pm 1.1$ \\
\hline CCL-2 & $-3.2 \pm 0.4$ \\
\hline IL- $1 \beta$ & $-2.7 \pm 0.2$ \\
\hline MMP-1 & $-2.3 \pm 0.3$ \\
\hline
\end{tabular}

Abbreviations: IGF-1: insulin-like growth factor-1; PAI-1: plasminogen activator inhibitor-1; FGF-2, -7: fibroblast growth factor-2, -7; Col: collagen; Angpt-1: angiopoietin-1; CTGF: connective tissue growth factor; WISP-1: WNT inducible signaling pathway protein-1; CTSG: cathepsin G; CTSK: cathepsin K; Tagln: transgelin; ITGA1: integrin alpha 1; ITGB6: integrin beta 6; TIMP-1: tissue inhibitor metalloproteinase-1; MMP-1, -7: metalloproteinase-1, -7; CCL-2: chemokine (C-C motif) ligand-2; IL-1 $\beta$ : interleukin-1 beta. 
survival (IGF-1, FGF-7), vascular maturation and homeostasis (Angpt-1, FGF-2), matrix structure and remodeling (collagens, cathepsins, PAI-1, TIMP-1), cytoskeleton regulation (integrins, transgelin), and WNT signaling (WISP-1); and down-regulated expression of genes involved in inflammatory cell migration (IL-1 $\beta$, CCL-2), and matrix proteolysis (MMP-1, MMP-7).

\section{Conclusions}

In this study, Vicryl mesh closure served as an absorbable scaffold for infiltration of granulation tissue which became the recipient microvascular bed for skin graft revascularization. Laser speckle contrast imaging demonstrated graft perfusion as early as post-operative day 5 , even before complete epithelialization of skin graft interstices. This is consistent with animal skin grafting research demonstrating the early perfusion of human skin transplanted onto athymic mice via the process of inosculation, the fusion or anastomosis of two vascular lumens to form one continuous lumen [20] [21]. Visceral graft perfusion plateaued during post-operative weeks $2-3$ and did not change thereafter, suggesting that graft separation from underlying viscera was not initiated by changes in local perfusion.

Histologic analysis with immunochemical identity of endothelium confirmed a similar organization and gradient of vasculature in the excised, mature visceral skin graft compared to full-thickness human skin. Each tissue contained a superficial vascular plexus located within the papillary dermis which was supplied by larger vessels from the deeper dermis [22]. Despite nearly complete separation from underlying peritoneal contents, visceral skin graft perfusion remained constant, and histology revealed communication of feeding vessels of the mesentery, omentum, and peripheral abdominal wall with the dermal microvascular plexus.

Microscopy and RT-PCR were utilized to evaluate the cellular and molecular changes associated with visceral graft maturation and separation. Trichrome staining revealed the excised skin graft was composed of a robust dermal matrix which originated from visceral granulation tissue and graft dermis. Immunochemistry documented the presence of mesothelial cells throughout the matrix, particularly in close proximity to deep dermal blood vessels.

Following injury, mesothelial cells are reported to initiate complete regeneration of the mesothelium or the development of pathologic adhesions [23]. Normal mesothelial healing is unlike other epithelial surfaces. Mesothelial healing progresses diffusely across the exposed surface, whereas for other epithelia, healing occurs by centripetal migration of cells from the wound edge. A free-floating population of mesothelial cells migrates and attaches to injured serosa [24] [25]. The perivascular location of dermal mesothelial cells may reflect their pathway of arrival and/or signify their importance in granulation tissue angiogenesis and vascular remodeling.

During peritoneal repair, mesothelial cells synthesize extracellular matrix (ECM) molecules including collagen types I, II, and IV, fibronectin, and elastin. They also regulate ECM turnover by secreting proteases and antiproteases, in- 
cluding matrix metalloproteinases and tissue inhibitor of metalloproteinases, respectively. Furthermore, mesothelial cells control fibrin deposition and breakdown through production of tissue-type plasminogen activator (tPA), and its inhibitor, plasminogen activator inhibitor-1 (PAI-1) [26] [27] [28]. Hence, the mesothelial cells present in the skin graft dermal matrix may be the sentinel cells which are necessary for remodeling of visceral granulation tissue into dermal matrix, and vital for separation of matrix from peritoneal contents, attempting to "reperitonealize" the abdominal cavity.

Granulation tissue is characterized by fibroblast proliferation and ECM deposition. Following tissue injury, fibroblasts acquire smooth muscle features including expression of $\alpha$-SM actin as they differentiate into myofibroblasts, the predominant cells involved in ECM contraction during repair [29]. In the resolution phase of healing, there is a loss of cells including myofibroblasts by apoptosis. The fibroblasts that remain in granulation tissue after the epithelial defect is closed revert to a more quiescent, noncontractile phenotype and lack $\alpha$-SM actin microfilament bundles that were present during the contractile phase of healing [30] [31]. Immunohistochemical investigation of visceral skin graft tissue revealed lack of myofibroblasts within the dermal matrix suggesting graft separation occurs following remodeling of granulation tissue.

Global transcription profiling of wounded keratinocyte cultures and epithelial tumor cells illustrates the importance of proteolysis and matrix remodeling in the integration of cell proliferation, motility, and differentiation in tissue repair [32] [33]. Therefore, we examined the expression of a focused panel of genes known to be important in ECM remodeling and wound repair (Table 1). Fine control of proteolysis reorganizes ECM architecture which affects the dynamics of cell-ECM interactions involving integrins, releases bioactive ECM molecules such as collagen fragments, and activates growth factors including IGF-1 and FGF-7 which stimulate cellular migratory and proliferative behavior [34] [35]. Current data suggests PAI-1 may function as a rheostat to regulate the spatial-temporal control of pericellular proteolysis in response to tissue injury [36]. Hence, PAI-1 may orchestrate the local proteolysis necessary for visceral skin graft maturation and separation.

Metalloproteinases were traditionally considered to be the major mediators of ECM degradation due to their extracellular location and enzymatic stability at neutral $\mathrm{pH}$ [37]. In contrast, cathepsins were reported as intracellular proteases involved in protein turnover. However, under specific physiologic conditions, the cathepsins can also be secreted into the extracellular space where they can remain proteolytically active and degrade various components of the ECM [38] [39]. Therefore, cathepsin activity at the dermal matrix-peritoneal cavity boundary may be important in graft separation.

The importance of IGF-1 and FGF-7 signaling in the skin is evident from original studies with IGF and FGF receptor null mice, which demonstrated hypotrophic skin with reduced number and size of hair follicles in these knockout mice [40] [41]. In addition to their role in skin homeostasis, multiple studies 
suggest a role for IGF-1 and FGF-7 in skin repair. In vitro, both growth factors have been shown to stimulate keratinocyte proliferation and migration, collagen production by fibroblasts, and granulation tissue maturation [42] [43].

Transcript analysis of visceral skin grafts revealed down-regulation of genes. Two metalloproteinases, MMP-1 and MMP-7, were down-regulated, while the expression of MMP-2 and MMP-9 remained unchanged in visceral skin grafts compared to control skin. Revascularization is an invasive process which requires proteolytic activity of the migrating cells. MMP-1, -2, -7, and -9 are involved in initiation of angiogenesis and vascular regression [44] [45]. Quiescent endothelial cells produce little or no MMP's, while active and invasive endothelium requires MMP activity [46]. At the time of visceral graft separation and excision, perfusion remained constant, and graft endothelium was likely nonproliferative and without need for MMP activity.

Two genes whose products are important inflammatory mediators were down-regulated in visceral skin graft tissue. The CCL-2 gene, its protein product a chemokine important in monocyte trafficking and endothelial proliferation [47], was down-regulated in graft tissue. IL- $1 \beta$ gene expression was also reduced. Previous research demonstrated the important activity of these mediators during the early inflammatory phase of wound healing, and their reduced expression during the later remodeling phase of wound repair [48] [49]. Reduced expression of CCL- 2 and IL- $1 \beta$ in the separating visceral skin graft may be an indicator of reduced peritoneal inflammation.

In summary, this study documented the ability of a noninvasive imaging technology to accurately determine visceral skin graft perfusion and temporal revascularization. Histologic and molecular analysis of excised graft tissue revealed the presence of mesothelial cells, absence of myofibroblasts, and expression of genes important in ECM regulation. In future research, we plan to investigate the temporal changes in the cellular and molecular environment involved in the formation of visceral granulation tissue utilizing microfluidic single-cell gene expression analysis of cells isolated from the black foam at serial wound VAC changes. Using specific cell surface markers, flow cytometry will be used to determine the time of arrival and disappearance of endothelial cells, mesothelial cells, and myofibroblasts. To conserve precious DNA, changes in gene expression from these cell populations will be determined by digital droplet PCR. Finally, we plan to elucidate the anatomic change in graft blood supply from its initial vertical source, the granulation tissue adherent to viscera and omentum, to its later horizontal source at graft separation, the circumferential abdominal wall, using simultaneous planar laser speckle contrast imaging and dimensional indocyanine green angiography. Understanding the biology of visceral granulation tissue formation and remodeling may guide therapeutic strategies for managing and improving healing of the open abdomen.

\section{References}

[1] Demetriades, D. and Salim, A. (2014) Management of the Open Abdomen. Surgical 
Clinics of North America, 94, 131-153. https://doi.org/10.1016/j.suc.2013.10.010

[2] Roberts, D.J., Bobrovitz, N., Zygum, D.A., et al. (2015) Indictions for Use of Damage Control Surgery and Damage Control Interventions in Civilian Trauma Patients: A Scoping Review. Journal of Trauma and Acute Care Surgery, 78, 1187-1196. https://doi.org/10.1097/TA.0000000000000647

[3] Jernigan, T.W., Fabian, T.C. and Croce, M.A., et al. (2003) Staged Management of Giant Abdominal Wall Defects. Annals of Surgery, 238, 349-357. https://doi.org/10.1097/01.sla.0000086544.42647.84

[4] Leppaniemi, A. and Tukiainen, E. (2013) Reconstruction of Complex Abdominal Wall Defects. Scandinavian Journal of Surgery, 102, 14-19. https://doi.org/10.1177/145749691310200104

[5] Regner, J.L., Kobayaski, L. and Coimbra, R. (2012) Surgical Strategies for Management of the Open Abdomen. World Journal of Surgery, 36, 497-510. https://doi.org/10.1007/s00268-011-1203-7

[6] Wang, T.Y., Elliot, R. and Low, D.W. (2013) Damage Control Abdomen: Single-Stage Reconstruction Using a Vicryl Mesh Buttress. Annals of Plastic Surgery, 121, 324-330.

[7] Fabian, T.C., Croce, M.A., Pritchard, F.E., et al. (1994) Planned Ventral Hernia: Staged Management for Acute Abdominal Wall Defects. Annals of Surgery, 219, 643-653. https://doi.org/10.1097/00000658-199406000-00007

[8] Howdiesell, T.R., Proctor, C.D., Sternberg, E., et al. (2004) Temporary Abdominal Closure Followed by Definitive Abdominal Wall Reconstruction of the Open Abdomen. American Journal of Surgery, 188, 301-306. https://doi.org/10.1016/j.amjsurg.2004.03.007

[9] Chiara, O., Cimbanassi, S., Biffl, W., et al. (2016) International Consensus Conference on Open Abdomen in Trauma. Journal of Trauma and Acute Care Surgery, 80, 173-183. https://doi.org/10.1097/TA.0000000000000882

[10] Roberts, D.J., Ball, C.G., Feliciano, D.V., et al. (2016) History of the Innovation of Damage Control for Management of Trauma Patients: 1902-2016. Annals of Surgery, $\mathbf{x x}, 1-11$.

[11] Cheesborough, J.E., Park, E., Sovza, J.M., et al. (2014) Staged Management of the Open Abdomen and Enteroatmospheric Fistulae Using Split-Thickness Skin Grafts. The American Journal of Surgery, 207, 504-511. https://doi.org/10.1016/j.amjsurg.2013.07.040

[12] Nilsson, G.E., Zhai, H., Farahmand, S., et al. (2009) Cutaneous Bioengineering Instrumentation Standardization: The Tissue Viability Imager. Skin Research and Technology, 15, 6-15. https://doi.org/10.1111/j.1600-0846.2008.00330.x

[13] McGuire, P.G. and Howdieshell, T.R. (2010) The Importance of Engraftment in Flap Revascularization: Confirmation by Laser Speckle Perfusion Imaging. Journal of Surgical Research, 164, e201-e212. https://doi.org/10.1016/j.jss.2010.07.059

[14] Khan, B., Rangasamy, S., McGuire, P.G. and Howdieshell, T.R. (2013) The Role of Monocyte Subsets in Myocutaneous Revascularization. Journal of Surgical Research, 183, 963-975. https://doi.org/10.1016/j.jss.2013.02.019

[15] Howdieshell, T.R., McGuire, P.G., Maestas, J., et al. (2011) Pattern Recognition Receptor Gene Expression in Ischemia-Induced Flap Revascularization. Surgery, 150, 418-428. https://doi.org/10.1016/j.surg.2011.06.037

[16] Briers, J.D. (2001) Laser Doppler, Speckle, and Related Techniques for Blood Perfusion Mapping and Imaging. Physiological Measurement, 22, R35-R55. 
https://doi.org/10.1088/0967-3334/22/4/201

[17] Choi, B., Kang, N.M. and Nelson, J.S. (2004) Laser Speckle Imaging for Monitoring Blood Flow Dynamics in the in Vivo Rodent Dorsal Skin Fold Model. Microvascular Research, 68, 143-160. https://doi.org/10.1016/j.mvr.2004.04.003

[18] Kawai, T., Tominaga, S., Hiroi, S., et al. (2016) Peritoneal Malignant Mesothelioma (PMM), Primary Peritoneal Serous Carcinoma (PPSC) and Reactive Mesothelial Hyperplasia (RMH) of the Peritoneum: Immunohistochemical and Fluorescence in Situ Hybridization (FISH) Analyses. Journal of Clinical Pathology, 69, 706-712. https://doi.org/10.1136/jclinpath-2015-203211

[19] Hinz, B., Phan, S.H., Thannickal, V.J., et al. (2012) Recent Developments in Myofibroblast Biology: Paradigms for Connective Tissue Remodeling. American Journal of Pathology, 180, 1340-1355. https://doi.org/10.1016/j.ajpath.2012.02.004

[20] Ucuzian, A.A., Gassman, A.A., East, A.T., et al. (2010) Molecular Mediators of Angiogenesis. Journal of Burn Care \& Research, 31, 1-28. https://doi.org/10.1097/BCR.0b013e3181c7ed82

[21] Plenat, F., Vignaud, J.M., Guerret-Stocker, S., et al. (1992) Host-Donor Interactions in Healing of Human Split-Thickness Skin Grafts onto Nude Mice: In Situ Hybridization, Immunohistochemical, and Histochemical Studies. Transplantation, 53, 1002-1020. https://doi.org/10.1097/00007890-199205000-00008

[22] Shirskin, E.A., Gurfinkel, Y.I., Priezzhev, A.V., et al. (2017) Two-Photon Autofluorescence Lifetime Imaging of Human Skin Papillary Dermis in Vivo: Assessment of Blood Capillaries and Structural Proteins Localization. Scientific Reports, 7, Article No. 1171.

[23] Liu, Y., Dong, Z., Liu, H., et al. (2015) Transition of Mesothelial Cell to Fibroblast in Peritoneal Dialysis: EMT, Stem Cell or Bystander? Peritoneal Dialysis International, 35, 14-25. https://doi.org/10.3747/pdi.2014.00188

[24] Mutsaers, S.E., Prele, C.M.A., Pengelly, S., et al. (2016) Mesothelial Cells and Peritoneal Homeostasis. Fertility and Sterility, 106, 1018-1024.

https://doi.org/10.1016/j.fertnstert.2016.09.005

[25] Foley-Comer, A.J., Herrick, S.E., Al-Mishlab, T., et al. (2002) Evidence for Incorporation of Free-Floating Mesothelial Cells as a Mechanism of Serosal Healing. Journal of Cell Science, 115, 1383-1389.

[26] Saed, G.M., Zhang, W., Chegini, N., et al. (1999) Alteration of Type I and III Collagen Expression in Human Peritoneal Mesothelial Cells in Response to Hypoxia and Transforming Growth Factor-Beta-1. Wound Repair and Regeneration, 7, 504-510. https://doi.org/10.1046/j.1524-475X.1999.00504.x

[27] Ma, C., Tarnuzzer, R.W. and Chegini, N. (1999) Expression of Matrix Metalloproteinases and Tissue Inhibitor of Matrix Metalloproteinases in Mesothelial Cells and Their Regulation by Transforming Growth Factor-Beta-1. Wound Repair and Regeneration, 7, 477-485. https://doi.org/10.1046/j.1524-475X.1999.00477.x

[28] Dobbie, J.W. and Jasani, M.K. (1997) Role of Imbalance of Intracavity Fibrin Formation and Removal in the Pathogenesis of Peritoneal Lesions in CAPD. Peritoneal Dialysis International, 17, 121-124.

[29] Hinz, B. (2016) The Role of Myofibroblasts in Wound Healing. Current Research in Translational Medicine, 64, 171-177. https://doi.org/10.1016/j.retram.2016.09.003

[30] Desmouliere, A., Darby, I.A. and Gabbiani, G. (2003) Normal and Pathologic Soft Tissue Remodeling: Role of the Myofibroblast with Special Emphasis on Liver and Kidney Fibrosis. Laboratory Investigation, 83, 1689-1707.

https://doi.org/10.1097/01.LAB.0000101911.53973.90 
[31] Gerarduzzi, C. and DiBattista, J.A. (2017) Myofibroblast Repair Mechanisms Post-Inflammatory Response: A Fibrotic Perspective. Inflammation Research, 66, 451-465. https://doi.org/10.1007/s00011-016-1019-x

[32] Fitsialos, G., Chassot, A.A., Turchi, L., et al. (2007) Transcriptional Signature of Epidermal Keratinocytes Subjected to in Vitro Scratch Wounding Reveals Selective Roles for $\mathrm{ERK}^{1} \frac{1}{2}, \mathrm{p} 38$, and Phosphatidylinositol 3-Kinase Signaling Pathways. The Journal of Biological Chemistry, 282, 15090-15102. https://doi.org/10.1074/jbc.M606094200

[33] Kan, J.S., DeLassus, G.S., D’Souza, K.G., et al. (2010) Modulators of Cancer Cell Invasiveness. Journal of Cellular Biochemistry, 111, 791-796. https://doi.org/10.1002/jcb.22794

[34] Czekay, R.P., Wilkins-Port, C.E., Higgins, S.P., et al. (2011) PAI-1: An Integrator of Cell Signaling and Migration. International Journal of Cell Biology, 2011, Article ID: 562481. https://doi.org/10.1155/2011/562481

[35] Cheng, C.F., Fan, J., Bandyopahdhay, B., et al. (2008) Profiling Motility Signal-Specific Genes in Primary Human Keratinocytes. Journal of Investigative Dermatology, 128, 1981-1990. https://doi.org/10.1038/jid.2008.34

[36] Simone, T.M., Higgins, C.E., Czekay, R.P., et al. (2014) Serpine 1: A Molecular Switch in the Proliferation-Migration Dichotomy in Wound "Activated" Keratinocytes. Advances in Wound Care, 3, 281-290. https://doi.org/10.1089/wound.2013.0512

[37] Werb, Z. (1997) ECM and Cell Surface Proteolysis: Regulating Cellular Ecology. Cell, 91, 439-442. https://doi.org/10.1016/S0092-8674(00)80429-8

[38] Turk, B., Turk, D. and Turk, V. (2000) Lysosomal Cysteine Proteases: More than Scavengers. Biochimica et Biophysica Acta, 1477, 98-111. https://doi.org/10.1016/S0167-4838(99)00263-0

[39] Vasiljeva, O., Reinheckel, T., Peters, C., et al. (2007) Emerging Roles of Cysteine Cathepsins in Disease and Their Potential as Drug Targets. Current Pharmaceutical Design, 13, 387-403. https://doi.org/10.1016/S0092-8674(00)80429-8

[40] Liu, J.P., Baker, J., Perkins, A.S., et al. (1993) Mice Carrying Null Mutations of the Genes Encoding Insulin-Like Growth Factor 1 (IGF-1) and Type I IGF Receptor (IGF1r). Cell, 75, 59-72.

[41] Marti, G.P., Mohebi, P., Liu, L., et al. (2008) KGF-1 for Wound Healing in Animal Models. Methods in Molecular Biology, 423, 383-391.

https://doi.org/10.1007/978-1-59745-194-9_30

[42] Haase, I., Evans, R., Pofahl, R., et al. (2003) Regulation of Keratinocyte Shape, Migration, and Wound Epithelialization by IGF-1 and EGF Dependent Signaling Pathways. Journal of Cell Science, 116, 3227-3238. https://doi.org/10.1242/jcs.00610

[43] Yang, Y., Fu, X. and Li, J. (2002) Effect of Keratinocyte Growth Factor on Proliferation of Human Adult Keratinocytes. Chinese Journal of Traumatology, 5, 342-345.

[44] Van Hinsbergh, V.W. and Koolwijk, P. (2008) Endothelial Sprouting and Angiogenesis: Matrix Metalloproteinases in the Lead. Cardiovascular Research, 78, 203-212. https://doi.org/10.1093/cvr/cvm102

[45] Calcagni, M., Althaus, M.K., Knapik, A.D., et al. (2011) In Vivo Visualization of the Origination of Skin Graft Vasculature in a Wild-Type/GFP Crossover Model. Microvascular Research, 82, 237-245. https://doi.org/10.1016/j.mvr.2011.07.003

[46] Hanemaajjer, R., Koolwijk, P., le Clercq, L., et al. (1993) Regualtion of Matrix Metalloproteinases (MMPs) Expression in Human Vein and Microvascular Endothelial 
Cells. Biochemical Journal, 296, 803-809. https://doi.org/10.1042/bj2960803

[47] Weber, K.S.C., Nelson, P.J., Grone, H.J., et al. (1999) Expression of CCR2 by Endothelial Cells. Arteriosclerosis, Thrombosis, and Vascular Biology, 19, 2085-2098. https://doi.org/10.1161/01.ATV.19.9.2085

[48] Barrientos, S., Stojadinovic, D., Golinko, M.S., et al. (2008) Growth Factors and Cytokines in Wound Healing. Wound Repair and Regeneration, 16, 585-601. https://doi.org/10.1111/j.1524-475X.2008.00410.x

[49] Eming, S.A., Krieg, T. and Davidson, J.M. (2007) Inflammation in Wound Repair: Molecular and Cellular Mechanisms. Journal of Investigative Dermatology, 127, 514-523. https://doi.org/10.1038/sj.jid.5700701 